\title{
Applying Kahoot in Thai Language and Culture Curriculum: Analysis of the Relationship among Online Cognitive Failure, Flow Experience, Gameplay Anxiety and Learning Performance
}

\author{
Jian-Hong Ye, Nitiwat Watthanapas, and Yu-Feng Wu
}

\begin{abstract}
The benefits of game-based learning have been confirmed by many studies, and it has also been proven to be a method that can bring meaningful learning to learners. However, its application in Taiwan's higher education stage is still infrequent, and only few related studies. Therefore, this study uses Kahoot with an interactive response system (IRS) mechanism as one of the curriculum teaching tools. The research adopted purposive sampling method. Participants were students from two universities in northern Taiwan who took Thai language and culture courses. The total number of valid participants was 103 , including 25 males $(29.8 \%)$ and 59 females $(\mathbf{7 0 . 2 \%})$. This study was based on the theory of cognitive learning of multimedia learning, and the design of Kahoot's game content. Based on the special CATLM and focus influence model, six research hypotheses were proposed to build a research model. The results showed that online cognitive failure was negatively correlated with gameplay flow; online cognitive failure was positively correlated with gameplay anxiety; gameplay flow was positively correlated with learning performance; gameplay anxiety was not correlated with learning performance; anxiety does not necessarily affect the effectiveness of game-based learning.
\end{abstract}

Index Terms - Game-based learning, instant response system, internet cognitive failure, Kahoot, Thai language and culture.

\section{INTRODUCTION}

With the advent of the digital age, it has become more common to integrate technical tools into teaching. Technical tools not only enable students to participate in learning, but also make learning more diverse and interesting [1]. Advances in computer and multimedia technologies have allowed educators to design and develop more meaningful learning activities [2]. On the other hand, game-based learning is considered one of the best practice in education. Past research also supports game based learning, which is an effective instrument for teachers in the classroom because it employs students in reviewing content, critical thinking and

Manuscript received March 18, 2020; revised June 15, 2020

Jian-Hong Ye is with the Department of Industrial Education and Institute for Research Excellence in Learning Sciences, and Chinese Language and Technology Center, National Taiwan Normal University, Taiwan (e-mail: kimpo30107@yahoo.com.tw).

Nitiwat Watthanapas is with the BA Program in Southeast Asian Languages and Cultures, National Chengchi University, Taiwan (e-mail: nitiwat2012@gmail.com).

Yu-Feng $\mathrm{Wu}$ is with the Graduate Institute of Sport, Leisure and Hospitality Management, National Taiwan Normal University, Taiwan (e-mail: garywu821822@gmail.com). problem solving [3].

Furthermore, related research indicated that meaningful learning occurs when learners make conscious efforts in the cognitive process of selecting, organizing, and integrating existing knowledge and new information [4]. In contrast, when comparing with traditional learning methods, game-based learning is likely to be more fully address the way young people learn today and make them more successful in meaningful learning [5], [6]. Therefore, a good applied educational game can create a meaningful learning process for learners.

In traditional classrooms, teachers often ask students questions during lectures and provide feedback based on their personal responses, while instant response technology enables teachers to speedily assess every student in the classroom and find misunderstandings or perceptions that need re-teaching [7]. In addition, the Instant Response System (IRS) has been used to enhance students' learning in classroom activities [1], IRS can help assess students understanding, vote for students to participate in knowledge building, data collection, enhance classroom dynamics, and improve the specificity of students' overall learning experience [8]. In line with this, Kahoot is an instant response game system designed for interactive learning and can be used by scholars of all ages [9]. Moreover, Kahoot has been shown to improve learners' achievement [1]. Therefore, this study uses Kahoot as the teaching tool for this study.

How the human cognitive system interacts with gameplay is a research topic worthy of discussion. For example, when learners experience high-level online cognitive failures, they may have poor learning feeling perception [10]. Therefore, in recent years, the cognition of learners has paid much attention to emotions. At the same time, the relationship between students' emotions and academic performance has also been regarded as an important issue in education [11], [12]. As always, research shows that when actively engaged in learning, learners can bring positive learning results [13]. However, learners with high levels of anxiety will produce negative learning experiences [14].

Using new learning education models for meaningful activities in the virtual world, for a more meaningful activity in a technology-rich world which allows educational games to promote meaningful learning [15]. Related research pointed out that in the multimedia learning process, it can be regarded as the process of individuals acquiring knowledge from information, and also for the learners to actively acquire meaning and process information [16]. Meaningful learning 
includes cognitive processing, comprising constructing connections between graphics and language [4]. Education scholars suggest that when designing learning materials for students, the use of multimedia learning principles can promote deep learning, also called meaningful learning [17]. Among them, Cognitive-Affective Theory of Learning with Media (CATLM) proposed by Moreno (2006) is widely used to explain learners' cognitive, emotional reactions and changes in the multimedia learning process [18]. Thus, this study proposes CATLM as an important theoretical framework for this study.

Based on the above literature, this study believes that online cognitive failure is one of the important factors affecting game-based learning, and that learners' Kahoot gameplay flow and gameplay anxiety in Thai language and culture courses are related to the performance of course learning. Therefore, this research builds a research model based on the framework of focus influence model; and explores the relationship between online cognitive failure, gameplay flow, gameplay anxiety, and learning performance.

\section{LITERATURE REVIEW}

\section{A. Online Cognitive Failure}

Cognitive failure is often referred to as subjective cognitive failure or subjective cognition because it is an individual's perception of their own cognitive function [19]. Cognitive failure is also known as the inability to successfully perform tasks that people might do every day [20]. This refers to changes in perception, memory, or behavior and errors in simple tasks that can happen to almost everyone [21]. Reports on cognitive failure may deepen our understanding of how cognitive processes work in real life [22]. People with cognitive failure tend to have difficulty in focusing, are irritable, and are prone to errors in cognitive tasks [23]. In addition, cognitive failure on the Internet has been used as a performance explanatory variable for digital learning tasks. It is clear that individuals with high levels of failure on the Internet are easily attentive and error-prone when they are online [24]. A study has indicated that Internet cognitive failure is negatively related to learning affective performance [25]. Therefore, this study uses online cognitive failure to explore learners' perception of Kahoot's cognitive failure in Thai language and culture courses, and analyzes the relationship between online cognitive failure, gameplay flow and gameplay anxiety. In this study, online cognitive failure refers to learners who are prone to distraction and have lack of concentration when watching online information.

\section{B. Gameplay Flow}

An optimal experience occurs when an individual is engaged in an activity and feels focused, interesting, and interested, this is known as flow experience [26]. The flow experience also refers to a state of mind, which is characterized by a concentration and concentration in fun activities [27]. At the same time, flow experience reflects the balance between the user's skill and the challenge. When the skill is better than the challenge, the user will feel bored, and when the challenge is greater than the skill, the user will feel anxious, but if the skill and challenge are lower than the perceived standard, users' feel indifferent when valued [28]. When individuals are in a state of flow, they will feel high cognitive efficiency, high participation, and a high level of enjoyment [29]. At the same time, flow experience has a positive impact on emotions and behaviors in digital learning [30]. Therefore, this study uses online cognitive failure to explore learners' perception of Kahoot gameplay flow applied to Thai language and culture courses, and analyzes the relationship between gameplay flow and learning performance. In this study, game flow refers to the state of learner's concentration, immersion, dedication and enjoyment when participating in answering questions in Kahoot.

\section{Gameplay Anxiety}

Anxiety is a negative emotion that affects all aspects of people's daily lives [31]. Panic, nervousness, helplessness, fear, distress, shame, inability to cope, sweating palms, tight stomach, difficulty breathing and inattention when individuals feel anxious [32]. Anxiety is an evolutionary adaptive process commonly experienced in daily life [33] and negative emotions, such as learning anxiety, may lead to poor learning [34]. Related studies pointed out that the use of situational English vocabulary games based on cognitive complexity will increase students' English anxiety [35]. Therefore, this study uses gameplay anxiety to explore learners' perception of Kahoot's gameplay anxiety applied to Thai language and culture courses, and analyzes the relationship between gameplay anxiety, gameplay flow and game progress performance. In this study, game anxiety refers to the situation in which learners have concerns, fears, or nervousness when participating in answering questions on Kahoot.

\section{Learning Performance}

Knowledge growth of learners on specific learning topics can be a predictive indicator of learning [36], making academic performance as a change in learners' cognition and skills after receiving instruction [37]. One of the measures of learning effectiveness is the learning performance of learners [38]. Learning performance is often characterized by specific content areas, which provides teachers with the scope and sequence of developing knowledge and skills as students' progress [39]. Therefore, this study explores the learning effectiveness of Kahoot in Thai language and culture courses in terms of learning performance. In this study, learning performance refers to the progress of the learners' performance in participating in game-based learning activities.

\section{RESEARCH HYPOTHESES}

\section{A. The Relationship between Online Cognitive Failure and Gameplay Flow}

Cognitive failure is often called subjective cognitive failure or subjective cognition because it is an individual's perception of one's own cognitive function [19]. Cognitive failure may equally well reflect a decline in the efficiency of the perceived level of selective attention and a decline in the 
deployment of cognitive resources [40]. In addition, the flow experience is the overall experience that occurs when one goes all out [41]. Moreover, flow experience enables participants to focus and ignore irrelevant thoughts [42]. For example, when online users are completely immersed in online activities, they will experience the flow experience [43]. Therefore, when users experience cognitive failure, they will not be able to produce a good flow experience. In addition, related research further points out that Internet cognitive failure is negatively related to flow experience [10] In summary, this study uses online cognitive failure to explore the relationship between participants' gameplay flow in the context of Kahoot games. Thus, the hypothesis is as follow:

H1: Online cognitive failure is negatively related to gameplay flow.

\section{B. The Relationship between Online Cognitive Failure and Gameplay Anxiety}

Cognitive ability is also considered to be one of the most vital reasons in examining individual performance in dynamic learning structures [44]. Therefore, when cognitive failure occurs, individuals will be unable to successfully perform tasks that people may do every day [20]. Increased anxiety is usually associated with decreased cognitive function [45] and at the same time, a study has pointed out that cognitive failure is positively related to anxiety perception [46]. Another study has indicated that individuals' attention problems are related to anxiety [47]. In addition, some studies have confirmed that Internet cognitive failure is positively correlated with cognitive anxiety [10]. Therefore, according to the above literature this study uses online cognitive failure to explore the relationship between participants' gameplay anxiety in the context of Kahoot game. Thus, the hypothesis is as follow:

$\mathrm{H} 2$ : Online cognitive failure is positively correlated with gameplay anxiety.

\section{The Relationship between Gameplay Flow and Learning Performance}

Flow is the state of complete absorption and concentration of an activity by the student as it enhances the learning experience [48]. Studies have shown that flow experience has a positive impact on memory and understanding [26], so when learners are actively engaged in learning, they can positively affect learning outcomes [13]. Therefore, the flow experience can also have a positive impact on learning outcomes [49], and if learners are engaged in educational games, they will have a positive impact on learning [50]. At the same time, related studies showed that flow experience and learning performance are positively correlated [10], [51]. Therefore, according to the above literature, this study uses gameplay flow to explore the relationship between participants and their learning performance. Thus, the hypothesis is as follow:

H3: Gameplay flow is positively correlated with learning performance.

\section{Relationship between Gameplay Anxiety and Learning} Performance

The ability will decline if an individual has high sense of individuality or high pressure in teaching [52]. Previous studies have found that anxiety and its debilitating consequences have a destructive effect on learning [53], while high levels of anxiety have been shown to negatively affect the learning experience of college students [14]. For example, in the field of mathematics, mathematical anxiety may reduce future mathematical performance [54], it can be seen that learning anxiety has a negative impact on academic performance [55]. Thus, reducing learner anxiety perception is crucial for learners [56]. In addition, research indicated that in interactive competitions, anxiety is also considered a negative emotional state, but may help promote or weaken personal performance in the competition [57]. Therefore, according to the above literature, this study uses gameplay anxiety to explore the relationship between participants and learning performance. Thus, the hypothesis is as follow:

H4: Gameplay anxiety is negatively correlated with learning performance.

\section{RESEARCH DESIGN}

\section{A. Research Model}

CATLM focuses on cognitive and emotional processes in multimedia learning [58]. CATLM pointed out that by adding interesting materials, it will motivate learners to invest their energy in learning the topic. Although adding details can enhance the interest, it may cause learners to invest more cognitive resources [59]. In addition, an attention-to-affect model is used to explain how inattention affects related variables [60], [61]. Such as being unable to integrate the learner into the game learning context or increasing anxiety perception, etc. Therefore, this study compiles relevant literature on online cognitive failure, gameplay flow, gameplay anxiety, and learning performance. Based on the CATLM theory, four research hypotheses are proposed to construct the following research model. As seen in Fig. 1.

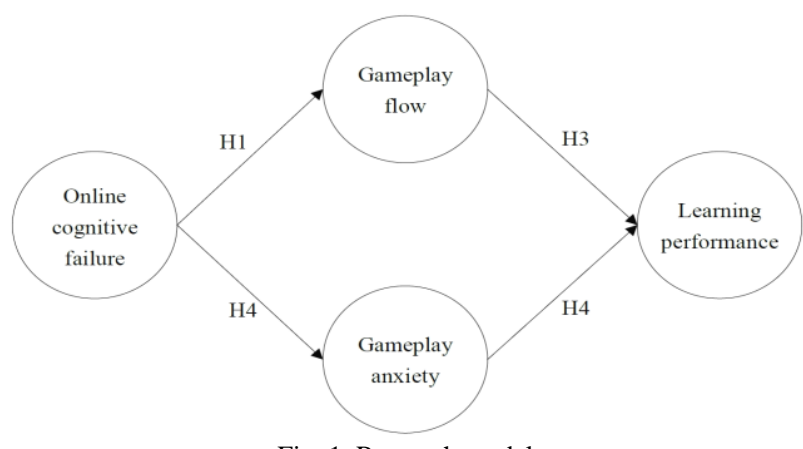

Fig. 1. Research model.

\section{B. Teaching Tool}

Kahoot is a real-time platform for game-based learning and a free foundational evaluation tool that is now commonly used in education [62], while Kahoot is essentially entertaining, it is a web software used in the field of education. It allows teachers and curriculum designers to integrate teaching content through quiz-like games [63]. Therefore, using Kahoot for games, both teachers and 
learners can engage in student-centered substantive discussions [64]. As can be seen from the above, Kahoot is a good teaching aid, so this study uses Kahoot as the course teaching tool for this study.

Accordingly, CATLM, affective factors can facilitate learning by inspiring learners to devote more resources while learning. In line with this, emotional factors have an indirect effect on learning by increasing or decreasing motivation, which in turn affects cognitive participation [59]. From the perspective of CATLM, when an individual's visual cognition is overloaded, that is, failure to create meaningful learning processes [18]. Therefore, according to the assumption of CATLM, the cognitive principles of instructional design can be derived [65]. This research is based on the CATLM theory to design game content for Thai language and culture courses. The game design and game topics for the following nine themes includes Thai language and character development, historical and political background, geographic and economic development, Buddhism and religious rituals, royal family, life and important festivals, folk customs, food culture and Thai current affairs issues which can be seen in Fig. 2 and Fig. 3. For example, the title of the game is: Thailand International Airport Suvarnabhumi Airport. What does Suvarnabhumi mean? "Land of Freedom", "Golden Land", "Sacred Land", "Beautiful Land"; Which one of the ending words should be used by males? “ครับ”; “ครบ”; “คร้บ”; “คร่บ” etc.

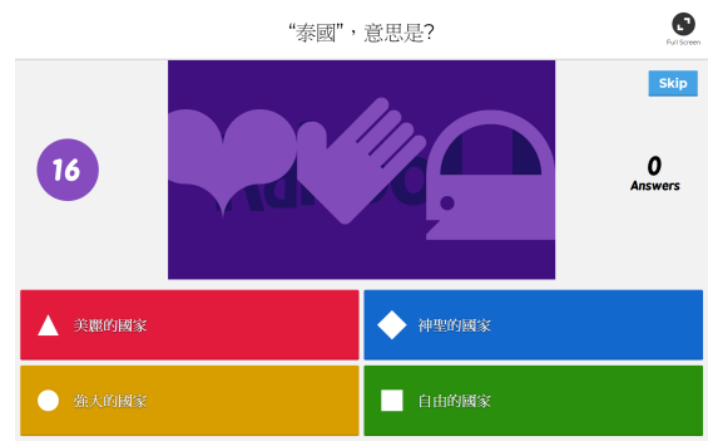

Fig. 2. Thai language and culture topics for Kahoot games.

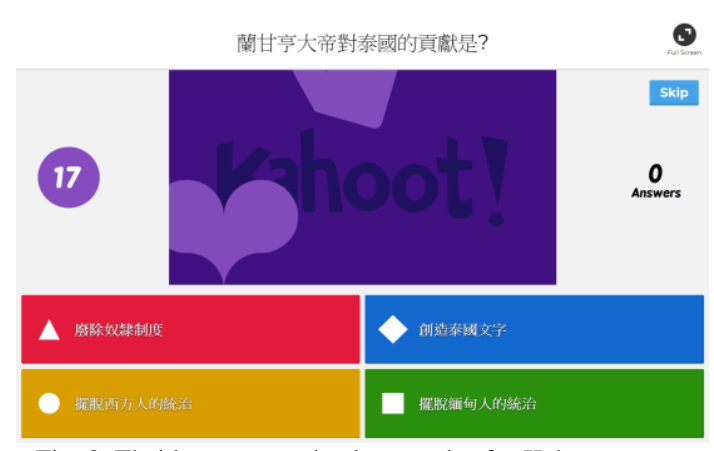

Fig. 3. Thai language and culture topics for Kahoot games.

\section{Teaching Procedures}

This study used purposive sampling method to conduct a quasi-experimental design teaching experiment for a national university and a national science and technology university in Taipei. Participants were students who partake Thai language and culture classes. A total of 8 weeks (10th to 18th week) of teaching experiments. Participants were asked to play for 15 minutes to review the content of the course of the previous week. Participants were asked to fill out the questionnaire on the $8^{\text {th }}$ week.

\section{Research Participants}

There were 103 participants in this study, after deletion of 19 invalid data, 84 valid data were analyzed, with an effective recovery rate of $81.6 \%$. A total of 25 males $(29.8 \%), 59$ females $(70.2 \%)$, national university $45(53.6 \%)$ and 39 students from a national science and technology university (46.4\%). The average age of the participants were 20.26 years (standard deviation is 1.622 years).

\section{E. Measurement}

The questionnaire scale for this study was translated and revised from related studies, and verified by two experts and scholars in the field of education. The questionnaire adopts the 5-point Likert scale ( 1 to 5 indicates very disagree to strongly agree) as the evaluation criteria.

\section{1) Online cognitive failure}

Cognitive failure of the Internet has resulted in a decrease in the efficiency of selective attention perception and a weakening of cognitive resource capabilities [23]. Based on the above concepts, this study adapted Hong, Hwang, Liu, Ho, and Chen (2014) Online Cognitive Failure Scale [40] to measure learners' perception of cognitive failure of online information.

\section{2) Gameplay flow experience}

Flow is a mental state in which an individual is immersed in an activity [66]. Based on the above concepts, this study adapted the flow experience scale [10] proposed by Hong et al. (2016) to measure learners' perception of Kahoot game investment situation.

\section{3) Gameplay anxiety}

Studies have shown that anxiety can produce psychological reactions such as panic, nervousness, fear, inability to cope and lack of concentration [32]. Based on the above concepts, this study adapted the anxiety scale [67] proposed by Hong, Lin, Hwang, Tai, and Kuo (2015) to measure the perception of gameplay anxiety of learners during the course review (learning) through Kahoot.

\section{4) Learning performance}

The study test content of this study includes Thai language and script development, historical and political background, geography and economic development, Buddhism and religious rituals, royal family, life and important festivals, folk customs, food culture and Thai current affairs issues, etc. The final exam quiz consisted of 50 questions each. The second study test was conducted by two experts with expertise in Thai language or Thai culture.

\section{DATA ANALYSIS}

\section{A. Item Analysis}

Scholars suggest that the internal validity can be confirmed by factor loading (FL), and the test value should be higher than .50 [68], [69]; The items of this study was that the online cognitive failure was deleted from 7 to 6 questions, the gameplay flow was deleted from 9 to 7 questions, and the gameplay anxiety was deleted from 10 to 8 questions. 
This study uses the measurement of the external validity of the items to determine the interpretation range of the study [70], and Table II shows that the $t$ value is higher than 21.022 $(p * * *<0.001)$, which clearly shows that all the retained questions have good external validity [71].

\section{B. Construct Reliability and Validity Analysis}

Reliability: Taber (2017) suggested that Cronbach's $\alpha$ should be higher than .70 [72], while Hair et al. (2010) suggested that the CR value should exceed .70 [68], and the Cronbach's $\alpha$ value in this study was between .934 and .964 , CR values range from .916 to .956 . Convergence validity: Hair et al. (2010) pointed out that the factor loading (FL) value should be higher than .50 [68], and the FL value of online cognitive failure in this study was between .811 to .920 . The FL value of the gameplay flow was between .687 and .877, and the FL value of gameplay anxiety is between .752 and .935 which is shown in Table II. Hair, Ringle, and Sarstedt (2011) suggested that the average variance extracted (AVE value must be greater than .50 [73], and the AVE values of each construct in this study ranged from .611 to .782, as shown in Table I.

Construct discriminative validity analysis: Carter (2016) indicated that the AVE root value of each construct is greater than the Pearson correlation coefficient value of other construct, which means that the construct has discriminative construct validity [74]. Test results showed that all construct has discriminative construct validity, which can be seen in Table II.

TABLE I: ITEM ANALYSIS OF RELIABILITY AND VALIDITY

\begin{tabular}{|c|c|c|c|c|}
\hline Items & $\mathrm{M}$ & SD & FL & $t$ value \\
\hline \multicolumn{5}{|c|}{$\begin{array}{l}\text { Online cognitive failure } \\
\mathrm{M}=2.042, \mathrm{SD}=.747, \text { Cronbach's } \alpha=.943, \mathrm{CR}=.956, \mathrm{AVE}=.782\end{array}$} \\
\hline $\begin{array}{l}\text { 1. I often read the wrong message so I have to } \\
\text { read it repeatedly to understand the correct } \\
\text { meaning. }\end{array}$ & 1.89 & .830 & .899 & 21.022 \\
\hline $\begin{array}{l}\text { 2. The messages I read often have to be } \\
\text { re-read repeatedly to understand their } \\
\text { meaning. }\end{array}$ & 2.07 & .833 & .879 & 22.795 \\
\hline $\begin{array}{l}\text { 3. When I browse the screen, I often cannot } \\
\text { find the information I need. }\end{array}$ & 1.94 & .833 & .920 & 21.223 \\
\hline $\begin{array}{l}\text { 4. If there is too much information on the } \\
\text { screen, I cannot find the information I } \\
\text { need. }\end{array}$ & 2.18 & .880 & .892 & 22.682 \\
\hline & 2.1 & .801 & .900 & 23.977 \\
\hline 6. I often forget wl & 2.07 & .902 & .811 & 21.041 \\
\hline \multicolumn{5}{|l|}{$\begin{array}{l}\text { Gameplay flow } \\
M=4.138, S D=605, \text { Cronbach's } \alpha=\end{array}$} \\
\hline $\mathrm{M}=4.138, \mathrm{SD}=.605$, Cronbach's $\alpha=.934$ & $\mathrm{CR}$ & 6 , & $z=.6$ & \\
\hline $\begin{array}{l}\text { 1. During game based-learning, I don't know } \\
\text { what I want to do, but I still do it. }\end{array}$ & 4.15 & .709 & .850 & 53.898 \\
\hline $\begin{array}{l}\text { 2. After game-based learning, I was a bit } \\
\text { unable to return to my mind (I still thought } \\
\text { about the game after the event). }\end{array}$ & 4.04 & .702 & 687 & 52.696 \\
\hline $\begin{array}{l}\text { 3. During the game-based learning process, I } \\
\text { was fully focused and didn't pay attention } \\
\text { to what happened around me. }\end{array}$ & 4.18 & .643 & .774 & 59.556 \\
\hline $\begin{array}{l}\text { 4. In the process of game-based learning, I } \\
\text { can continuously overcome difficulties and } \\
\text { continue to invest. }\end{array}$ & 4.20 & .741 & 692 & 51.986 \\
\hline $\begin{array}{l}\text { 5. After game-based learning was over, I } \\
\text { couldn't play anymore, and I found that I } \\
\text { was a bit lost. }\end{array}$ & 4.33 & .658 & .877 & 60.013 \\
\hline $\begin{array}{l}\text { 6. During game-based learning, I } \\
\text { experienced the realm of selflessness. }\end{array}$ & 3.99 & .799 & .715 & 45.746 \\
\hline $\begin{array}{l}\text { 7. During the game-based learning process, I } \\
\text { was so attentive that I didn't feel anything } \\
\text { when time passed. }\end{array}$ & 4.08 & .748 & .851 & 50.045 \\
\hline
\end{tabular}

\begin{tabular}{|c|c|c|c|c|}
\hline Items & M & SD & FL & $t$ value \\
\hline \multicolumn{5}{|c|}{$\begin{array}{l}\text { Gameplay anxiety } \\
\mathrm{M}=2.885, \mathrm{SD}=.715, \text { Cronbach's } \alpha=.964, \mathrm{CR}=.946, \mathrm{AVE}=.689\end{array}$} \\
\hline $\begin{array}{l}\text { 1. In this game, I am worried that I make } \\
\text { mistake in the game. }\end{array}$ & 2.50 & 1.000 & 935 & 22.913 \\
\hline $\begin{array}{l}\text { 2. In this game, I get nervous and forget the } \\
\text { answer that I know. }\end{array}$ & 2.79 & 1.088 & .869 & 23.067 \\
\hline $\begin{array}{l}\text { 3. In this game I get worried that others are } \\
\text { better than me. }\end{array}$ & 2.63 & 1.128 & .827 & 21.382 \\
\hline $\begin{array}{l}\text { 4. In this game I worry about not being able } \\
\text { to cope easily. }\end{array}$ & 2.71 & 1.093 & .752 & 22.762 \\
\hline $\begin{array}{l}\text { 5. I get distracted in the game and it affects } \\
\text { my performance. }\end{array}$ & 2.83 & 1.149 & .836 & 22.591 \\
\hline $\begin{array}{l}\text { 6. In this game, I get distracted and can't } \\
\text { think of the answer. }\end{array}$ & 2.61 & 1.109 & .793 & 21.551 \\
\hline $\begin{array}{l}\text { 7. In this game, people often pay attention to } \\
\text { the performance of others and do not pay } \\
\text { attention. }\end{array}$ & 2.45 & 1.036 & .777 & 22.127 \\
\hline $\begin{array}{l}\text { 8. In this game, I was flustered to answer this } \\
\text { question. }\end{array}$ & 2.39 & 1.030 & .838 & 21.294 \\
\hline
\end{tabular}

TABLE II: CONSTRUCT DISCRIMINATIVE VALIDITY ANALYSIS

\begin{tabular}{lcccc}
\hline \hline \multicolumn{1}{c}{ Construct } & 1 & 2 & 3 & 4 \\
\hline 1. Online cognitive failure & $(.884)$ & & & \\
2. Gameplay flow & -.374 & $(.781)$ & & \\
3. Gameplay anxiety & .130 & -.184 & $(.830)$ & \\
4. Learning performance & -.285 & .485 & -.742 & $(1)$ \\
\hline \hline
\end{tabular}

\section{RESULTS}

\section{A. Analysis of Learning Performance}

The results of the analysis of learning performance showed that the average number was 6.167 points, the standard deviation was 9.433 points, and the median was 3.375 points, as shown in Table III. The learners' final exam scores were also significantly higher than the midterm exams, shown in Table IV.

\section{TABLE III: ANALYSIS OF LEARNING PERFORMANCE}

\begin{tabular}{lcccccc}
\hline \hline \multicolumn{1}{c}{ Construct } & \multicolumn{1}{c}{ M } & SD & Med. \\
\hline Learning performance & \multicolumn{7}{c}{6.167} & 9.433 & 3.375 \\
\hline \multicolumn{7}{c}{ TABLE IV: ANALYSIS OF LEARNING PERFORMANCE } \\
\hline \hline \multicolumn{1}{c}{ Construct } & $N$ & $M$ & $S D$ & $t$ & Comparison & $d$ \\
\hline 1.Mid-term exam & 84 & 93.036 & 16.964 & $5.725^{* * *}$ & $2>1$ & .264 \\
2.Final Exam & 84 & 88.723 & 15.675 & & & \\
\hline \hline
\end{tabular}

\section{B. Research Model Verification}

The research analysis results in Fig. 4 showed that: online cognitive failure is negatively correlated with gameplay flow ( $\beta=-.460 * * *, t=-3.358)$; online cognitive failure is positively correlated with gameplay anxiety $(\beta=.600 * * *, t=$ 8.270); gameplay flow was positively correlated with learning performance $(\beta=.479 * * *, t=3.553)$; gameplay anxiety was not correlated with learning performance $(\beta=$ $-.068, t=-.979)$.

The explanatory power of online cognitive failure on gameplay flow is $21.2 \%$, and $f 2$ was .269 ; the explanatory power of online cognitive failure on gameplay anxiety is $36 \%$, and $f 2$ was .53.6; The explanatory power of learning performance was $24.9 \%$, and $f 2$ was .714 . 


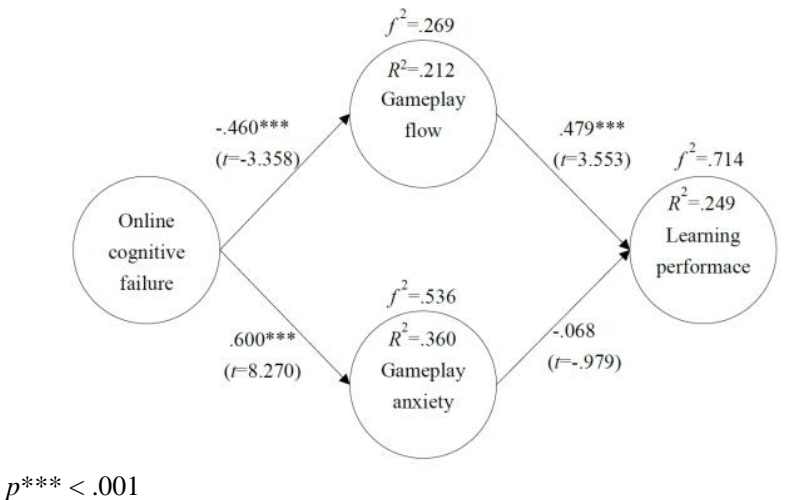

Fig. 4. Model verification model.

\section{Indirect Effects Analysis}

A study of game-based learning by Hong et al. (2016) showed that online cognitive failure was indirectly negatively related to game progress [10], and indirect effect analysis results showed that online cognitive failure was indirectly negatively related to learning performance $(\beta=$ $-.269 * *)$ shown in Table $\mathrm{V}$, which was consistent with the findings of (Hong et al. 2016).

TABLE V: INDIRECT EFFECTS ANALYSIS

\begin{tabular}{lcc}
\hline \hline Construct & \multicolumn{2}{c}{ Online cognitive failure } \\
\hline & $\beta$ & CI \\
\hline Learning performance & $-.269^{* *}$ & {$[-.410,-.094]$} \\
\hline \hline$p^{* *<.01}$ & &
\end{tabular}

\section{RESEARCH DISCUSSION}

\section{A. Negative Correlation between Online Cognitive Failure and Gameplay Flow}

The flow experience mentioned by Yoshida et al. (2014) is the overall experience that occurs when one goes all out [41]. In addition, Chang et al. (2017) flow experience allows participants to focus and ignore irrelevant thoughts [42], while Van Noort et al. (2012) pointed out that when online users are completely immersed in online activities, they will experience the flow experience [43]. However, Jessen et al. (2014) stated that cognitive failure is called subjective cognitive failure or subjective cognition, and it refers to people's perception of their own cognitive functions [19]. On the other hand, Hong et al. (2014) stated that cognitive failure may equally well reflect the decline in the efficiency of the perceptual level of selective attention and the decline in the deployment of cognitive resources [40]. Therefore, when users experience cognitive failure, they will not be able to produce a good flow experience. Moreover, the research by Hong et al. (2016) further pointed out that Internet cognitive failure is negatively related to flow experience [10]. It can be seen that when learners have a high level of network cognition failure, they cannot enter the gameplay flow state. The analysis results of this study showed that online cognition failure has a negative correlation with gameplay flow.

\section{B. Online Cognitive Failure is Positively Correlated with Gameplay Anxiety}

Laughery et al. (2006) believe that cognitive ability is one of the most vital indicator in examining individual performance in dynamic learning structures [44]. Therefore, Jose and George (2017) believe that when individuals experience cognitive failure, they will be unable to successfully perform tasks that people may do every day [20]. Meissel and Salthouse (2016) point out that increased anxiety is often associated with decreased cognitive function [45]. At the same time, Matthews and Wells (1988) showed that cognitive failure and anxiety perception are positively related [46], while Kendall and Pimental (2003) research also showed that the individual's concentration problem is related to anxiety [47]. In addition, research by Hong et al. (2016) also confirmed that Internet cognitive failure is positively correlated with cognitive anxiety [10]. It can be seen from the above that when learners have a high level of online cognition failure, they will also have a higher perception of gameplay anxiety. The analysis results of this study showed that online cognition failure was positively correlated with gameplay anxiety.

\section{Positive Relationship between Gameplay Flow and Learning Performance}

Buil et al. (2019) stated that the flow experience is a state where students fully absorb and concentrate on an activity because it enhances the learning experience [48], while research by Erhel and Jamet (2019) showed that flow experience has a positive impact on memory and understanding [26]. In line with this, Su (2017) stated that when learners are actively engaged in learning, they will positively affect learning outcomes [13]. Therefore, Ho and Kuo (2010) pointed out that the flow experience can also have a positive impact on learning outcomes [49], and that learners will have a positive impact on learning if they are engaged in educational games [50]. At the same time, studies by Hong et al. (2016) and Hong et al. (2017) have shown that flow experience was positively related to learning performance [10], [51]. In summary, when the learner enters a state of flow, it will bring better results to the learning outcomes, and the analysis results of this study showed that gameplay flow was positively related to learning performance.

\section{No Correlation between Gameplay Anxiety and Learning Performance}

A study by Vitasari et al. (2010) showed that high levels of anxiety have shown a negative impact on the learning experience of college students [14], and it can be seen that learning anxiety has a negative impact on academic performance [55]. However, the analysis results of this study showed that there was no correlation between gameplay anxiety and learning performance. This may allow explanations from studies on other different points. For example, Hanin (2000) pointed out that in an interactive competition, anxiety is considered to be a negative emotional state, but may help promote personal performance in the competition [57]. In addition, some studies have pointed out that moderate anxiety perception can improve individual alertness and help focus their attention, thereby promoting complex cognitive functions [75]. In addition, studies in foreign language studies have shown that there was no significant relationship between student anxiety and 
academic performance in English Medium Instruction (EMI) courses [76]. Other study by Chanda and Guha (2018) have further shown [77] that no level of learning anxiety (i.e. low, medium and high) has a significant effect on the means of student learning ability. It is clear that anxiety in games does not necessarily cause negative learning outcomes. However, Abdous (2019) still suggests that learners' anxiety perception should be reduced [56].

\section{CONCLUSION AND IMPLICATIONS}

\section{A. Conclusion}

Previous studies showed that game-based learning is likely to more fully address the way young people learn today and make them more successful in meaningful learning [5], [6]. However, in Taiwan's higher education stage, the application of game-based learning is infrequent. Therefore, this study used Kahoot as a teaching tool in Thai language and culture curriculum and put forward six research hypotheses, and constructed a research model. This study showed that online cognitive failure was negatively correlated with gaming flow, online cognitive failure was positively correlated with gameplay anxiety, gaming flow was positively correlated with learning performance, and gameplay anxiety was not correlated with learning performance.

In addition, study showed that Kahoot can promote learners to achieve better learning achievements [1], and this study also confirms this part. After using the Kahoot course review tool, participants in this study improved their learning performance. The average improvement was 6.167 points $(S D=9.433)$, In addition, studies have shown that learning games require certain qualities that meet learning outcomes and learner engagement [78]. In this study, participants also had a high level of game flow when performing Kahoot answering activities $(M=4.138, S D=.605)$ which was consistent with the argument that learners bring meaningful learning with game-based learning.

Furthermore, a research has indicated that a multimedia environment can decrease student anxiety and offer a fewer stressful learning environment [79], and this study echoes the results of that research. Teaching experiment results in this study showed that gameplay anxiety's average perception was lower than the median $(M=2.885, S D=.715)$.

\section{B. Implications}

There are several disadvantages in traditional teaching methods. For example, during the first 10 to 20 minutes of the lesson until the last few minutes of the lesson, students' range of attention will continue to decline [80]. Therefore, making good use of educational games to assist teaching will help learners maintain their learning focus. Moreover, this study showed that when learners have a high level of gaming flow experience, it will bring better performance. Therefore, this study suggests that university teachers can use educational games with IRS characteristics as a teaching tool.

In addition, studies by Laing, Burns, and Baetu (2019) pointed out that higher-order cognitive abilities may reduce the impact of anxiety on learning [81], so this research also suggests that educators can teach learners how to be good in the process of game-based teaching, using cognitive strategies to reduce gameplay anxiety during the learning process. At the same time, Ardasheva, Carbonneau, Roo, and Wang (2018) also proposed that prior knowledge can reduce the negative relationship between anxiety and learning [82]. It can be inferred that when learners are more familiar with the learning content of the previous week, the less gameplay anxiety is generated when reviewing the course content with Kahoot. Therefore, it is also important for learners to effectively memorize the learning content of each week. Thus, teachers can provide adaptable memory strategies according to the characteristics of different learners to promote learners to obtain higher levels of learning effects.

\section{Implications for Future Studies}

Adopting an innovative gamified digital quiz app can effectively assess student achievement, especially formative assessments used after completing each topic [83]. However, the game results of the participants were not collected in this study, so this part cannot be analyzed. Therefore, in the future research, learners' previous performances can be collected for analysis with cognitive and affective performance, and time series analysis can also be performed to understand learners' learning situations at different learning times.

The subjective perception of cognitive decline is related to basic personality traits, which may partially reflect the processes associated with these traits [84], and personality traits were not used as a research change. Therefore, it is suggested that in future research, different personality traits can be used as independent variables in the research to understand the influence on cognitive variables. Sustained willingness has become an important research topic in the field of information systems research, and persistent intention of information systems describes the users' intention to decide to continue using a particular information system [85]. Accordingly, learners' intention to continue use Kahoot games as learning tools is an important topic for discussion. However, the variable of continuance intention to play has not been considered in this study, so this part can also be discussed in subsequent studies.

Research on learning and education is increasingly being influenced by embodied cognitive theories [86]. Embodied learning through games receive increasing attention in educational research. The dynamic stimulation of the limbs is believed to stimulate the brain and cognition, thereby strengthening learners' memory, performance, and learning retention. Therefore, in the follow-up studies, the effects on language and cultural courses can also be explored through embodied learning. In addition, the effects of games with embodied learning features and games without embodied learning features can be compared, so that there is a better understanding in the characteristics of different games.

\section{CONFLICT OF INTEREST}

The authors declare no conflict of interest.

\section{AUTHOR CONTRIBUTIONS}

First author conducted the research and collected data; second and third author analyzed the data; all authors wrote the paper; all authors had approved the version. 


\section{ACKNOWLEDGEMENT}

This work was financially supported by the "Institute for Research Excellence in Learning Sciences" and "Chinese Language and Technology Center" of National Taiwan Normal University (NTNU) from The Featured Areas Research Center Program within the framework of the Higher Education Sprout Project by the Ministry of Education (MOE) in Taiwan.

\section{REFERENCES}

[1] C. C. Lee, Y. Hao, K. S. Lee, S. C. Sim, and C. C. Huang, "Investigation of the effects of an online instant response system on students in a middle school of a rural area," Computers in Human Behavior, vol. 95, pp. 217-223, 2019.

[2] C. Y. Chang, C. H. Kao, G. J. Hwang, and F. H. Lin, "From experiencing to critical thinking: A contextual game-based learning approach to improving nursing students' performance in electrocardiogram training," Educational Technology Research and Development.

[3] R. Dellos, "Kahoot! A digital game resource for learning," International Journal of Instructional Technology and Distance Learning, vol. 12, no. 4, pp. 49-52, 2015.

[4] R. E. Mayer and R. Moreno, "Nine ways to reduce cognitive load in multimedia learning," Educational Psychologist, vol. 38, pp. 43-52, 2003.

[5] J. P. Gee, "What video games have to teach us about learning and literacy," ACM Computers in Entertainment, vol. 1, pp. 1-4, 2003.

[6] D. Shaffer, How Computer Games Help Children Learn, New York, NY: Palgrave Macmillan, 2006.

[7] G. A. Stoica and R. P. Pein, "Taking the pulse of the classroom with response technology," ELearning \& Software for Education, vol. 1, 2016.

[8] H. T. T. Chen, "Investigating the effects of web-based instant response system on learning and teaching in pre-service teacher courses," in Shaping the Future of Education, Communication and Technology, W. W. K. Ma, W. W. L. Chan, and C. M. Cheng, Eds. Singapore, SG: Springer, 2019, pp. 141-151.

[9] D. A. L. Tan, B. C. Lee, M. Ganapathy, and S. A. A. Kasuma, "Language learning in the 21st century: Malaysian ESL students' perceptions of Kahoot!" International Journal of Virtual and Personal Learning Environments, vol. 9, no. 2, pp. 55-71, 2019.

[10] J. C. Hong, K. H. Tai, M. Y. Hwang, and Y. C. Kuo, "Internet cognitive failure affects learning progress as mediated by cognitive anxiety and flow while playing a Chinese antonym synonym game with interacting verbal-analytical and motor-control," Computers \& Education, vol. 100, pp. 32-44, 2016

[11] M. T. Cheng, T. Su, W. Y. Huang, and J. H. Chen, “ An educational game for learning human immunology: What do students learn and how do they perceive?" British Journal of Educational Technology, vol. 5 , no. 5 , pp. 820-833, 2014.

[12] S. F. Verkijika and L. Wet, "Using a brain-computer interface (BCI) in reducing math anxiety: Evidence from South Africa," Computers \& Education, vol. 81, pp. 113-122, 2015.

[13] C. H. Su, "The effects of students' learning anxiety and motivation on the learning achievement in the activity theory based gamified learning environment," EURASIA Journal of Mathematics, Science and Technology Education, vol. 13, no. 5, pp. 1229-1258, 2017.

[14] P. Vitasari, M. N. A. Wahab, A. Othman, T. Herawan, and S. K. Sinnadurai, "The relationship between study anxiety and academic performance among engineering students," Procedia - Social and Behavioral Sciences, vol. 8, pp. 490-497, 2010.

[15] K. Nachimuthu and G. Vijayakumari, "Role of educational games improves meaningful learning," Journal of Educational Technology, vol. 8, no. 2, pp. 25-33, 2011.

[16] C. C. Chang, Y. J. Tsai, and L. L. S. Lwo, "The impacts of different modalities od multi-media for Tang poetry learning," Educational Technology \& Learning, vol. 3, no. 1, pp. 71-92, 2015.

[17] R. E. Mayer, Multimedia Learning, Cambridge, UK: Cambridge University Press, 2001.

[18] R. Moreno, "Does the modality principle hold for different media? A test of the method-affects-learning hypothesis," Journal of Computer Assisted Learning, vol. 22, no. 3, pp. 149-158, 2006.

[19] F. Jessen, R. E. Amariglio, M. Boxtel, M. Breteler, M. Ceccaldi, G. Chételat, and L. Glodzik, "A conceptual framework for research on subjective cognitive decline in preclinical Alzheimer's disease," Alzheimer's \& Dementia, vol. 10, no. 6, pp. 844-852, 2014.

[20] A. T. Jose and J. S. George, "Cognitive failure and general well-being among IT Professionals," International Journal of Research in Social Sciences, vol. 7, no. 3, pp. 635-642, 2017.

[21] T. Jankowski and W. Bąk, "Mindfulness as a mediator of the relationship between trait anxiety, attentional control and cognitive failures, A multimodel inference approach," Personality and Individual Differences, vol. 142, pp. 62-71, 2019.

[22] N. Carrigan and E. Barkus, "A systematic review of cognitive failures in daily life: Healthy populations, Neuroscience \& Biobehavioral Reviews, vol. 63, pp. 29-42, 2016.

[23] J. C. Hong, K. H. Tai, M. Y. Hwang, Y. C. Kuo, and J. S. Chen, "Internet cognitive failure relevant to users' satisfaction with content and interface design to reflect continuance intention to use a government e-learning system," Computers in Human Behavior, vol. 66, pp. 353-362, 2017.

[24] E. Whelan, N. Islam, and S. Brooks, Cognitive Control and Social Media Overload, 2017

[25] J. C. Hong, M. Y. Hwang, E. Szeto, C. R. Tsai, Y. C. Kuo, and W. Y. Hsu, "Internet cognitive failure relevant to self-efficacy, learning interest, and satisfaction with social media learning," Computers in Human Behavior, vol. 55, pp. 214-222, 2016.

[26] S. Erhel and E. Jamet, "Improving instructions in educational computer games: Exploring the relations between goal specificity, flow experience and learning outcomes," Computers in Human Behavior, vol. 91, pp. 106-114, 2019.

[27] D. J. Shernoff, M. Csikszentmihalyi, B. Schneider, and E. S. Shernoff, "Student engagement in high school classrooms from the perspective of flow theory," in Applications of Flow in Human Development and Education, M. Csikszentmihalyi, Ed. Dordrecht, DE: Springer, 2014, pp. $475-494$

[28] L. Gao, K. A. Waechter, and X. Bai, "Understanding consumers' continuance intention towards mobile purchase: A theoretical framework and empirical study-A case of China," Computers in Human Behavior, vol. 53, pp. 249-262, 2015.

[29] K. Asakawa, "Flow experience and autotelic personality in Japanese college students: How do they experience challenges in daily life?" Journal of Happiness Studies, vol. 5, no. 2, pp. 123-154, 2004.

[30] I. Rodríguez-Ardura and A. Meseguer-Artola, "Flow in e-learning: What drives it and why it matters," British Journal of Educational Technology, vol. 48, no. 4, pp. 899-915, 2017.

[31] D. Jiang, D. Zhang, Y. Chen, Z. He, Q. Gao, R. Gu, and P. Xu, “Trait anxiety and probabilistic learning: Behavioral and electrophysiological findings," Biological Psychology, vol. 132, pp. 17-26, 2018.

[32] H. Catlioglu, O. Birgin, S. Costu, and R. Gurbuz, "The level of mathematics anxiety among pre-service elementary school teachers," Procedia Social and Behavioral Sciences, vol. 1, pp. 1578-1581, 2009.

[33] A. Pittig, M. Treanor, R. T. LeBeau, and M. G. Craske, "The role of associative fear and avoidance learning in anxiety disorders: Gaps and directions for future research," Neuroscience \& Biobehavioral Reviews, vol. 88 , pp. 117-140, 2018.

[34] G. J. Hwang, T. C. Hsu, C. L. Lai, and C. J. Hsueh, "Interaction of problem-based gaming and learning anxiety in language students' English listening performance and progressive behavioral patterns," Computers \& Education, vol. 106, pp. 26-42, 2017.

[35] Q.-F. Yang, S.-C. Chang, G.-J. Hwang, and D. Zou, "Balancing cognitive complexity and gaming level: Effects of a cognitive complexity-based competition game on EFL students' English vocabulary learning performance, anxiety and behaviors," Computers \& Education.

[36] S. K. Carpenter, T. J. Lund, C. R. Coffman, P. I. Armstrong, M. H. Lamm, and R. D. Reason, "A classroom study on the relationship between student achievement and retrieval-enhanced learning," Educational Psychology Review, vol. 28, no. 2, pp. 353-375, 2016.

[37] G. Piccoli, R. Ahmad, and B. Lves, "Web-based virtual learning environments: A research framework and a preliminary assessment of effectiveness in basic IT skills training," MIS Quarterly, vol. 25, pp. 401-426, 2001.

[38] J. Lu, C. S. Yu, and C. Liu, "Learning style, learning patterns, and learning performance in a WebCT-based MIS course," Information \& Management, vol. 40, no. 6, pp. 497-507, 2003.

[39] T. Barnhart and E. Es, "Studying teacher noticing: Examining the relationship among pre-service science teachers' ability to attend, analyze and respond to student thinking," Teaching and Teacher Education, vol. 45, pp. 83-93, 2015.

[40] J. C. Hong, M. Y. Hwang, M. C. Liu, H. Y. Ho, and Y. L. Chen, "Using a 'prediction-observation-explanation' inquiry model to enhance 
student interest and intention to continue science learning predicted by their Internet cognitive failure," Computers \& Education, vol. 72, pp 110-120, 2014

[41] K. Yoshida, D. Sawamura, Y. Inagaki, K. Ogawa, K. Ikoma, and S Sakai, "Brain activity during the flow experience: A functional near-infrared spectroscopy study," Neuroscience Letters, vol. 573, pp. 30-34, 2014

[42] C. C. Chang, C. Liang, P. N. Chou, and G. Y. Lin, "Is game-based learning better in flow experience and various types of cognitive load than non-game-based learning? Perspective from multimedia and media richness," Computers in Human Behavior, vol. 71, pp. 218-227, 2017.

[43] G. Noort, H. A. Voorveld, and E. A. Reijmersdal, "Interactivity in brand web sites: Cognitive, affective, and behavioral responses explained by consumers' online flow experience," Journal of Interactive Marketing, vol. 26, no. 4, pp. 223-234, 2012

[44] K. R. Laughery, C. J. Lebiere, and S. Archer, "Modeling human performance in complex systems," in Handbook of Human Factors \& Ergonomics, G. Salvendy, Ed. Hoboken, NJ: Wiley, 2006, pp. 967-996.

[45] E. E. Meissel and T. A. Salthouse, "Relations of naturally occurring variations in state anxiety and cognitive functioning," Personality and Individual Differences, vol. 98, pp. 85-90, 2016.

[46] G. Matthews and A. Wells, "Relationships between anxiety, self-consciousness, and cognitive failure," Cognition and Emotion, vol 2, no. 2, pp. 123-132, 1988.

[47] P. C. Kendall and S. S. Pimentel, "On the physiological symptom constellation in youth with generalized anxiety disorder (GAD)," Journal of Anxiety Disorders, vol. 17, no. 2, pp. 211-221, 2003.

[48] I. Buil, S. Catalán, and E. Martínez, "The influence of flow on learning outcomes: An empirical study on the use of clickers," British Journal of Educational Technology, vol. 50, no. 1, pp. 428-439, 2019.

[49] L. A. Ho and T. H. Kuo, "How can one amplify the effect of e-learning? An examination of high-tech employees' computer attitude and flow experience," Computers in Human Behavior, vol. 26, no. 1, pp. 23-31 2010.

[50] J. Hamari, D. J. Shernoff, E. Rowe, B. Coller, J. Asbell-Clarke, and T. Edwards, "Challenging games help students learn: An empirical study on engagement, flow and immersion in game-based learning," Computers in Human Behavior, vol. 54, pp. 170-179, 2016.

[51] J. C. Hong, M. Y. Hwang, K. H. Tai, and P. H. Lin, "Intrinsic motivation of Chinese learning in predicting online learning self-efficacy and flow experience relevant to students' learning progress," Computer Assisted Language Learning, vol. 30, no. 6, pp. $552-574,2017$

[52] K. M. Cooper, V. R. Downing, and S. E. Brownell, "The influence of active learning practices on student anxiety in large-enrollment college science classrooms," International Journal of STEM Education, vol. 5, no. $1,2018$.

[53] H. Khoshsima, A. Sarani, and M. Ganji, "A dynamic intervention for removing learning anxiety: A field experiment on removing psychological barriers to speaking," International Journal of Behavioral Sciences, vol. 12, no. 1, pp. 25-31, 2018

[54] E. Carey, F. Hill, A. Devine, and D. Szücs, "The chicken or the egg? The direction of the relationship between mathematics anxiety and mathematics performance," Frontiers in Psychology, vol. 6, 2016.

[55] C. H. Su, "The effects of students' motivation, cognitive load and learning anxiety in gamification software engineering education: A structural equation modeling study," Multimedia Tools and Applications, vol. 75, no. 16, pp. 10013-10036, 2016.

[56] M. H. Abdous, "Influence of satisfaction and preparedness on online students' feelings of anxiety," The Internet and Higher Education, vol 41, pp. 34-44, 2019.

[57] Y. L. Hanin, Emotions in Sport, Champaign, IL: Human Kinetics, 2000.

[58] B. Park, J. L. Plass, and R. Brünken, "Cognitive and affective processes in multimedia learning," Learning and Instruction, vol. 29, pp $125-127,2014$

[59] T. Kühl, F. Moersdorf, M. Römer, and S. Münzer, "Adding emotionality to seductive details-Consequences for learning?" Applied Cognitive Psychology, vol. 33, no. 1, pp. 48-61, 2019.

[60] C. R. Critcher and M. J. Ferguson, "Affect in the abstract: Abstract mindsets promote sensitivity to affect," Journal of Experimental Social Psychology, vol. 47, no. 6, pp. 1185-1191, 2011.

[61] A. B. Satpute, J. Shu, J. Weber, M. Roy, and K. N. Ochsner, "The functional neural architecture of self-reports of affective experience,' Biological Psychiatry, vol. 73, no. 7, pp. 631-638, 2013.
[62] M. A. A. Ismail, A. Ahmad, J. A. M. Mohammad, N. M. R. M. Fakri, M. Z. M. Nor, and M. N. M. Pa, "Using Kahoot! as a formative assessment tool in medical education: A phenomenological study," BMC Medical Education, vol. 19, no. 1, 2019

[63] P. Bawa, "Using Kahoot to inspire," Journal of Educational Technology Systems, vol. 47, no. 3, pp. 373-390, 2019.

[64] L. Zucker and A. A. Fisch, "Play and learning with Kahoot!: Enhancing collaboration and engagement in grades 9-16 through digital games," Journal of Language and Literacy Education, vol. 15, no. 1, 2019.

[65] R. Moreno and R. Mayer, "Interactive multimodal learning environments," Educational Psychology Review, vol. 19, no. 3, pp. 309-326, 2007.

[66] M. Csikszentmihalyi, Flow: The Psychology of Optimal Experience, New York, NY: Harper and Row, 1990.

[67] J. C. Hong, M. P. Lin, M. Y. Hwang, K. H. Tai, and Y. C. Kuo, "Comparing animated and static modes in educational gameplay on user interest, performance and gameplay anxiety," Computers \& Education, vol. 88, pp. 109-118, 2015

[68] J. F. Hair, W. C. Black, B. J. Babin, and R. E. Anderson, Multivariate Data Analysis, 7th ed. Upper Saddle River, NJ: Pearson Prentice Hall, 2010.

[69] D. A. Kenny, B. Kaniskan, and D. B. McCoach, "The performance of RMSEA in models with small degrees of freedom," Sociological Methods \& Research, vol. 44, no. 3, pp. 486-507, 2015.

[70] M. K. Cor, "Trust me, it is valid: Research validity in pharmacy education research," Currents in Pharmacy Teaching and Learning, vol. 8, no. 3, pp. 391-400, 2016.

[71] S. B. Green and N. Salkind, Using SPSS for Windows and Macintosh: Analyzing and Understanding Data, 4th ed. Englewood Cliffs, NJ: Prentice-Hall, 2004.

[72] K. S. Taber, "The use of Cronbach's alpha when developing and reporting research instruments in science education," Research in Science Education, vol. 48, no. 6, pp. 1273-1296, 2018.

[73] J. F. Hair, C M. Ringle, and M. Sarstedt, "PLS-SEM: Indeed a silver bullet," Journal of Marketing Theory and Practice, vol. 19, no. 2, pp 139-152, 2011

[74] S. R. Carter, "Using confirmatory factor analysis to manage discriminant validity issues in social pharmacy research," International Journal of Clinical Pharmacy, vol. 38, no. 3, pp. 731-737, 2016.

[75] Z. Wang, S. L. Lukowski, S. A. Hart, I. M. Lyons, L. A. Thompson, Y. Kovas, and S. A. Petrill, "Is math anxiety always bad for math learning? The role of math motivation," Psychological Science, vol. 26, no. 12, pp. 1863-1876, 2015.

[76] N. F. B. C. Ghani, “Attitudes towards English medium instruction courses among second language learners in relation to learning anxiety and learning achievement," Southeast Asia Language Teaching and Learning, vol. 1, no. 1, pp. 38-47, 2018.

[77] T. Chanda and A. Guha, "Effect of learning anxiety on ability in learning of higher secondary students," Research Journal of Social Sciences, vol. 9, no. 8, pp. 101-108, 2018.

[78] G. Sriharee, "The design patterns for language learning and the assessment on game-based learning," International Journal of Information and Education Technology, vol. 10, no. 2, pp. 95-103, 2020.

[79] M. J. Shahi, "The impact of e-learning on improving Iranian EFL learners' language skills: Decreasing learning anxiety," Journal of Fundamental and Applied Sciences, vol. 8, no. 3, pp. 261-275, 2016.

[80] J. E. McLaughlin, M. T. Roth, D. M. Glatt, N. Gharkholonarehe, C. A. Davidson, L. M. Griffin, D. A. Esserman, and R. J. Mumper, "The flipped classroom: A course redesign to foster learning and engagement in a health professions school," Academic Medicine, vol. 89 , no. 2, pp. 236-243, 2014

[81] P. A. Laing, N. Burns, and I. Baetu, "Individual differences in anxiety and fear learning: The role of working memory capacity," Acta Psychologica, vol. 193, pp. 42-54, 2019.

[82] Y. Ardasheva, K. J. Carbonneau, A. K. Roo, and Z. Wang, "Relationships among prior learning, anxiety, self-efficacy, and science vocabulary learning of middle school students with varied English language proficiency," Learning and Individual Differences, vol. 61 , pp. 21-30, 2018.

[83] Z. Zainuddin, M. Shujahat, H. Haruna, and S. K. W. Chu, "The role of gamified e-quizzes on student learning and engagement: An interactive gamification solution for a formative assessment system," Computer \& Education, vol. 145, 2020.

[84] A. R. Sutin, D. Aschwanden, Y. Stephan, and A. Terracciano, "Five factor model personality traits and subjective cognitive failures," Personality and Individual Differences, vol. 155, pp. 109741, 2020. 
[85] Y. Lee and O. Kwon, "Intimacy, familiarity and continuance intention: An extended expectation-Confirmation model in web-based services," Electronic Commerce Research and Applications, vol. 10, no. 3, pp. 342-357, 2011.

[86] A. Skulmowski and G. D. Rey, "Embodied learning: Introducing a taxonomy based on bodily engagement and task integration," Cognitive Research: Principles and Implications, vol. 3, no. 1, 2018.

Copyright $\odot 2020$ by the authors. This is an open access article distributed under the Creative Commons Attribution License which permits unrestricted use, distribution, and reproduction in any medium, provided the original work is properly cited (CC BY 4.0).

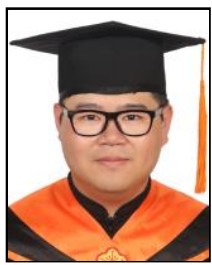

Jian-Hong Ye is a PhD candidate at the Department of Industrial Education, National Taiwan Normal University. He serves as a research assistant at the Institute for Research Excellence in Learning Sciences and Chinese Language and Technology Center, National Taiwan Normal University.

Mr. Ye's main research interests include digital learning, game-based learning, and design education.

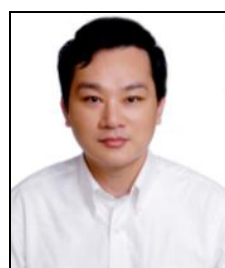

Nitiwat Watthanapas is a $\mathrm{PhD}$ student at the Graduate Institute of Curriculum and Instruction, National Taiwan Normal University. He serves as an adjunct lecturer at the BA Program in Southeast Asian Languages and Cultures, National Chengchi University.

Mr. Watthanapas's main research interests include learning, language learning.

curriculum and instruction quarterly, game-based

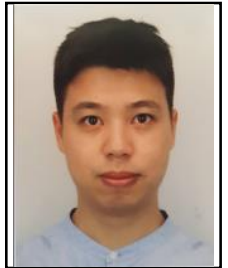

Yu-Feng $\mathbf{W u}$ is a $\mathrm{PhD}$ candidate at the Graduate Institute of Sport, Leisure and Hospitality Management, National Taiwan Normal University.

Mr. Wu's main research interests include organizational behavior, consumer behavior, sport wearables, e-sport and game-based learning. 